\title{
Evaluation of the Electrostatic Contribution to the Retention of Modified Nucleosides and Nucleobases by Zwitterionic Hydrophilic Interaction Chromatography
}

\author{
Diego García-Gómez, Encarnación Rodríguez-Gonzalo, and Rita Carabias-Martínez \\ Departamento de Química Analítica, Nutrición y Bromatología, Universidad de Salamanca, 37008 Salamanca, Spain \\ Correspondence should be addressed to Encarnación Rodríguez-Gonzalo, erg@usal.es
}

Received 20 December 2011; Accepted 10 January 2012

Academic Editors: T. Bolanca, A. M. Haji Shabani, and K. Ohyama

Copyright (C) 2012 Diego García-Gómez et al. This is an open access article distributed under the Creative Commons Attribution License, which permits unrestricted use, distribution, and reproduction in any medium, provided the original work is properly cited.

This work explores the benefits and limitations, on a quantitative basis, of using zwitterionic hydrophilic interaction chromatography (ZIC-HILIC) for the separation of several modified nucleosides and nucleobases of clinical interest. The target compounds were hydroxylated and methylated derivatives: 8-hydroxy-guanine, 8-hydroxy-guanosine, 8-hydroxy-2'-deoxyguanosine, 1-methyl-guanine, 7-methyl-guanine, and 9-methyl-guanine. A quantitative evaluation of the electrostatic interaction based on a systematic study of the nature and concentration of the salts in the mobile phase has been carried out. From the obtained results, it may be concluded that separation is based on a mechanism of partition and interaction through weak electrostatic forces: the contribution of the electrostatic interaction to the retention of the charged analytes reaching values between 25 and $52 \%$ at low salt concentration. However, the electrostatic contribution decreased progressively as the salt concentration rose.

\section{Introduction}

Hydrophilic interaction chromatography (HILIC) is a mode of chromatography in which polar compounds are retained using hydrophilic stationary phases combined with mobile phases with a high concentration of organic solvent and a small amount of water [1]. A partition mechanism between the aqueous layer associated with the stationary phase and the organic component of the mobile phase has been proposed to explain the type of separation that occurs in HILIC [1]. However, later studies have shown that the mechanism of retention involves more complex equilibria [2]. Moreover, the presence of charged sites in the stationary phase in zwitterionic hydrophilic chromatography (ZIC-HILIC) would propitiate the appearance of other retention mechanisms $[3,4]$.

Despite the many applications described in the literature, the retention mechanism in ZIC-HILIC is still under debate $[2,4-14]$.

The chromatographic behaviour of several modified nucleosides and nucleobases (MNNs) with different stationary phases in HILIC mode has been described previously [15], the zwitterionic stationary phase being the most suitable one for their separation. The MNNs selected were hydroxylated and methylated derivatives, used as biological markers of several diseases: 8-hydroxy-guanine (8OHGua), 8hydroxy-guanosine (8OHG), 8-hydroxy-2'-deoxyguanosine (8OH2dG), 1-methyl-guanine (1mGua), 7-methyl-guanine (7mGua), and 9-methyl-guanine (9mGua). The results obtained from the study of the different parameters affecting separation-content of organic solvent in the mobile phase, $\mathrm{pH}$, salt concentration, and temperature inside the columnshowed that separation in the ZIC-HILIC column was based on a mechanism of partition between the aqueous phase bound to stationary phase and the organic compound of mobile phase. However, the mechanism is complex, and it presumably involves other processes such as retention of the MNN with hydroxyl groups by hydrogen bonding or interaction through weak electrostatic forces for charged analytes.

In this work, we describe a quantitative evaluation of these electrostatic interactions in ZIC-HILIC in order to elucidate the contribution of the interactions to the retention 
of the target analytes. The evaluation was based on a detailed study of the influence of the type and concentration of the salt used.

Thus, the aim of the present work was to contribute to a better understanding of the retention mechanism of these compounds in ZIC-HILIC mode.

\section{Experimental}

2.1. Chemicals. Analytical standards of 8 -hydroxy-guanine (8OHGua), CAS RN [5614-64-2]; and 8-hydroxy-guanosine (8OHG), CAS RN [3868-31-3] were purchased from Cayman Chemical (Michigan, USA). 8-hydroxy-2'-deoxyguanosine (8OH2dG), CAS RN [88847-89-6]; 9-methyl-guanine (9mGua), CAS RN [5502-78-3]; 1-methyl-guanine (1mGua), CAS RN [938-85-2]; and 7-methyl-guanine (7mGua), CAS RN [578-76-7] were obtained from Sigma-Aldrich (Steinheim, Germany).

Working solutions were daily prepared at $5 \mu \mathrm{g} \mathrm{mL}^{-1}$ for $1 \mathrm{mGua}, 7 \mathrm{mGua}$, and $9 \mathrm{mGua}$, and at $3 \mu \mathrm{g} \mathrm{mL}^{-1}$ for $8 \mathrm{OH} 2 \mathrm{dG}$, $8 \mathrm{OHG}$, and $8 \mathrm{OHGua}$.

Acetonitrile (ACN) was of HPLC grade (Merck, Darmstadt, Germany). Ultrahigh-quality (UHQ) water was obtained with a Wasserlab (Noain, Spain) Ultramatic water purification system. All other chemicals were of analytical reagent grade.

2.2. Instrumentation. HPLC analyses were performed on a HP 1100 Series chromatograph from Agilent (Waldbronn, Germany). The Diode Array Detector (DAD) recorded the spectra in the 190-400 $\mathrm{nm}$ range. The analytical column was a ZIC-HILIC packed with $3.5 \mu \mathrm{m}$ particles from Merck (Darmstadt, Germany). Analyses were performed in isocratic elution: $80 \%$ ACN: $20 \%$ formic acid $\left(2.6 \mathrm{mM},{ }^{w}{ }^{\mathrm{w}} \mathrm{pH}=3.1\right)$ with variable concentration of ammonium or potassium perchlorate. Column temperature was set to $20^{\circ} \mathrm{C}$, flow rate at $0.5 \mathrm{~mL} \mathrm{~min} \mathrm{~m}^{-1}$, and an injection volume of $50 \mu \mathrm{L}$ in $\mathrm{ACN}$ was selected.

\section{Results and Discussion}

Application of the ZIC-HILIC mode to the separation of MNN has been described previously [15]. A mobile phase containing $80 \%$ ACN and $2.5 \mathrm{mM}$ formic acid $\left({ }_{\mathrm{w}}{ }^{\mathrm{w}} \mathrm{pH} 3.1\right)$ allowed appropriate resolution to be achieved. At that $\mathrm{pH}$ value, only methylated MNNs were in the protonated form, and hence electrostatic interactions with the sulfobetaine groups in the stationary phase could be expected for these analytes. Hydroxylated MNNs were not charged at ${ }_{w}{ }^{\mathrm{w}} \mathrm{pH}$ 3.1, and therefore different behavior that for methylated MNN would be expected.

\subsection{Effect of the Nature and Salt Concentration in the Mobile} Phase. Owing to the high organic content of the mobile phase in ZIC-HILIC, the number of salts available is limited to those showing acceptable solubility in organic medium, such as perchlorate or organic salts.
In HILIC mode, increases in salt concentrations usually lead to an increase in analyte retention [16]. Additionally, other effects may appear in ZIC-HILIC: for eluents with low salt concentration, ion exchange equilibrium should be established between the cations of the mobile phase in the stationary phase and the charged analytes.

We have previously reported the behavior of the target compounds in ZIC-HILIC mode for salt concentrations in the $0.25-200 \mathrm{mM}$ range for ammonium perchlorate and 0.25-5.0 mM for potassium perchlorate (because of its poor solubility) [15]. Briefly, two zones showing different behaviour were observed: at low salt concentrations $(0-2.5 \mathrm{mM})$, a strong decrease occurred in the retention of all the charged MNNs studied (methylated MNN at ${ }_{w}{ }^{\mathrm{w}} \mathrm{pH}$ 3.1), indicating that a decrease in electrostatic retention had taken place (Figure 1(a)). The electrostatic nature of this decrease was confirmed by the behaviour of hydroxylated MNNs, which were not charged at ${ }_{\mathrm{w}}{ }^{\mathrm{w}} \mathrm{pH}$ : 3.1 (Figure 1(b)), and by carrying out the same experiment at ${ }_{w}{ }^{\mathrm{w}} \mathrm{pH}$ : 6.7, where both the methylated and hydroxylated MNN were uncharged; both experiments resulted in the disappearance of this zone, confirming the electrostatic nature of the decrease. The other zone appeared at high salt concentrations (15-200 mM), pointing to an increase in retention and in agreement with the characteristics observed for a partition mechanism.

\subsubsection{Quantitative Evaluation of the Electrostatic Contribution} to Retention. The retention of a charged analyte $\left(\mathrm{BH}^{+}\right)$on the sulfonic group $\left(\mathrm{R}-\mathrm{SO}_{3}{ }^{-}\right)$of the stationary phase can be described according to

$$
\mathrm{BH}^{+}+\mathrm{RSO}_{3}{ }^{-} \mathrm{M}^{+} \longleftrightarrow \mathrm{RSO}_{3}{ }^{-} \mathrm{BH}^{+}+\mathrm{M}^{+},
$$

where $\mathrm{M}^{+}$represents the cation of the salt present in the eluent.

It has been reported $[2,4]$ that electrostatic interactions fit (2):

$$
k_{\mathrm{EI}}=A \frac{1}{\left[\mathrm{M}^{+}\right]},
$$

where $A$ is a constant similar to that described by McCalley $[2,4]$ :

$$
A \propto \frac{K\left[\mathrm{RSO}_{3}{ }^{-} \mathrm{M}^{+}\right]}{1+K_{a} /\left[\mathrm{H}^{+}\right]},
$$

$K$ being the equilibrium constant of (1), and $K_{a}$, the acidbase ionization constant of the analyte $\left(\mathrm{BH}^{+}\right)$.

Accordingly, a plot of the experimental retention factors $\left(k_{\exp }\right)$ against the inverse of the salt concentration $\left(\left[\mathrm{M}^{+}\right]^{-1}\right)$ should be a straight line, proportional to $A$, with the ordinate at the origin being zero if electrostatic interactions are the only retention mechanism (2). Experimentally, the values found for salt concentrations in the $0.25-2.5 \mathrm{mM}$ range (values of $\left[\mathrm{M}^{+}\right]^{-1}$ ranging from 4000 to $400 \mathrm{M}^{-1}$ ) fit a secondorder polynomial equation, with $r^{2}$ values between 0.945 and 0.989 for $\mathrm{NH}_{4}{ }^{+}$and between 0.913 and 0.957 for $K^{+}$, indicating the existence of a minor additional effect (Table 1). The presence of other nonelectrostatic retention mechanisms 


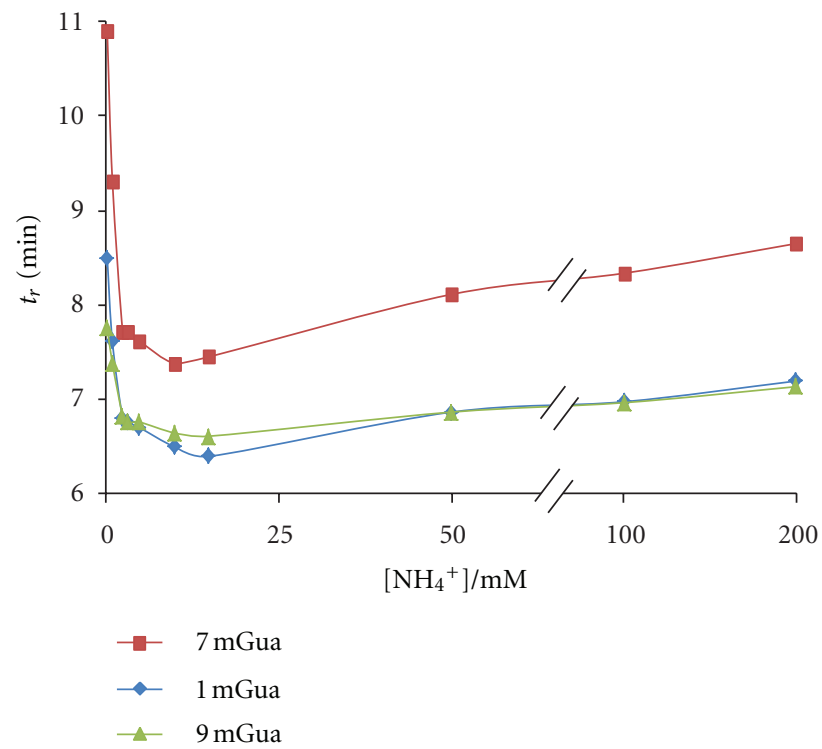

(a)

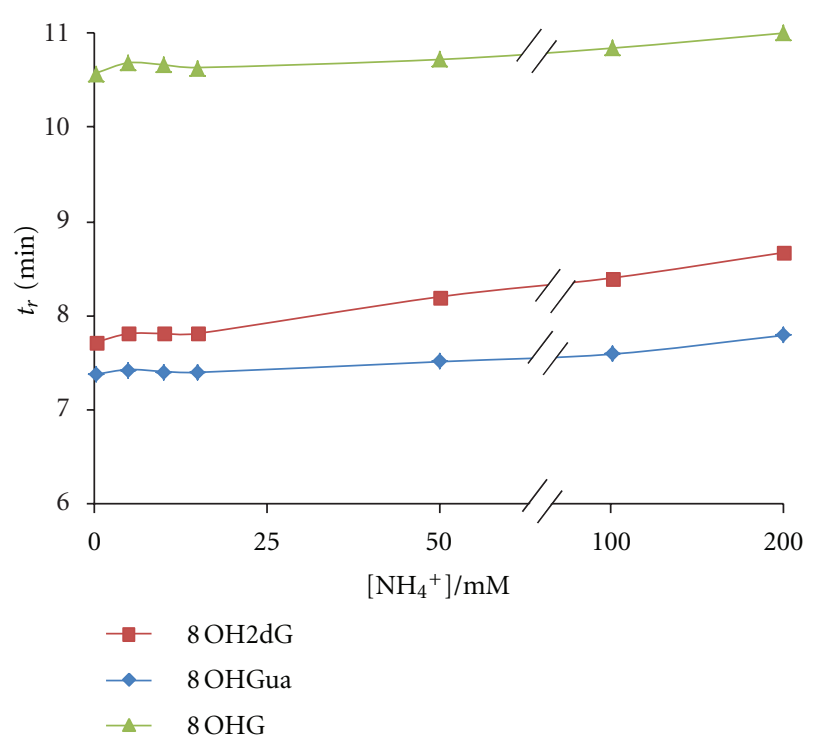

(b)

FIGURE 1: Plots of retention time $\left(t_{r}\right)$ versus ammonium perchlorate concentration for methylated MNNs (a) and hydroxylated MNNs (b).

TABle 1: Parameters of the equation for the second-order polynomial fitting of the experimental retention factors $\left(k_{\exp }\right)$ versus the inverse of the salt concentration $\left(\left[\mathrm{M}^{+}\right]^{-1}\right)^{(\mathrm{a})}$.

Modified nucleosides and nucleobases $k_{\exp }=a /\left[\mathrm{M}^{+}\right]^{2}+b /\left[\mathrm{M}^{+}\right]+c$ $\mathrm{M}^{+}$: Ammonium perchlorate

\begin{tabular}{|c|c|c|c|c|}
\hline & $R^{2}$ & $a$ & $b$ & $c$ \\
\hline 9mGua & 0.9538 & $-4 E-5$ & 0.3 & 1.3667 \\
\hline $1 \mathrm{mGua}$ & 0.9681 & $-3 E-5$ & 0.2 & 1.3969 \\
\hline \multirow[t]{3}{*}{$7 \mathrm{mGua}$} & 0.9782 & $-1 E-4$ & 0.7 & 1.5624 \\
\hline & \multicolumn{4}{|c|}{$\mathrm{M}^{+}$: Potassium perchlorate } \\
\hline & $R^{2}$ & $a$ & $b$ & $c$ \\
\hline 9mGua & 0.9392 & $-5 E-5$ & 0.3 & 1.3109 \\
\hline $1 \mathrm{mGua}$ & 0.9127 & $-7 E-5$ & 0.4 & 1.1628 \\
\hline 7mGua & 0.9574 & $-1 E-4$ & 0.8 & 1.3724 \\
\hline
\end{tabular}

(a) Isocratic elution: $80 \%$ ACN: $20 \%$ formic acid $\left(2.6 \mathrm{mM},{ }_{w}{ }^{\mathrm{w}} \mathrm{pH}=3.1\right)$ with variable concentrations of ammonium or potassium perchlorate. Temperature: $20^{\circ} \mathrm{C}$. Flow: $0.5 \mathrm{~mL} \mathrm{~min}{ }^{-1}$. Injection: $50 \mu \mathrm{L}$ in CAN.

TABle 2: Contribution of electrostatic interactions to the ZIC-HILIC retention of the positively charged MNNs, at different salt concentrations ${ }^{(a)}$. $\%$ of electrostatic interaction in retention

Charged MNN Ammonium perchlorate

\begin{tabular}{|c|c|c|c|c|c|}
\hline & $0.25 \mathrm{mM}$ & $0.50 \mathrm{mM}$ & $1.00 \mathrm{mM}$ & $2.50 \mathrm{mM}$ & $\left(k_{\mathrm{EI}}\right)_{0.25 \mathrm{mM}}$ \\
\hline $9 \mathrm{mGua}$ & 25 & 21 & 17 & 6 & 0.45 \\
\hline $1 \mathrm{mGua}$ & 28 & 20 & 16 & 4 & 0.75 \\
\hline \multirow[t]{3}{*}{$7 \mathrm{mGua}$} & 52 & 46 & 39 & 23 & 1.66 \\
\hline & \multicolumn{5}{|c|}{ Potassium perchlorate } \\
\hline & $0.25 \mathrm{mM}$ & $0.50 \mathrm{mM}$ & $1.00 \mathrm{mM}$ & $2.50 \mathrm{mM}$ & $\left(k_{\mathrm{EI}}\right)_{0.25 \mathrm{mM}}$ \\
\hline $9 \mathrm{mGua}$ & 26 & 24 & 20 & 6 & 0.54 \\
\hline 1mGua & 38 & 32 & 29 & 9 & 0.99 \\
\hline $7 \mathrm{mGua}$ & 49 & 44 & 38 & 16 & 1.85 \\
\hline
\end{tabular}

(a) Isocratic elution: $80 \% \mathrm{ACN}: 20 \%$ formic acid $\left(2.6 \mathrm{mM},{ }_{w}{ }^{\mathrm{w}} \mathrm{pH}=3.1\right)$ with variable concentrations of ammonium or potassium perchlorate. Temperature:

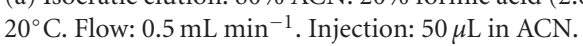


(e.g., partition mechanism) is indicated by the fact that values for the ordinate at the origin are different from zero (Table 1) and a straight line was not obtained.

Therefore, bearing in mind that the experimental retention factors $\left(k_{\exp }\right)$ must be the sum of the contribution of the electrostatic $\left(k_{\mathrm{EI}}\right)$ and nonelectrostatic $\left(k_{\mathrm{NEI}}\right)$ interactions:

$$
k_{\exp }=k_{\mathrm{EI}}+k_{\mathrm{NEI}},
$$

and substituting (2) in (4), we have

$$
k_{\exp }=A \frac{1}{\left[\mathrm{M}^{+}\right]}+k_{\mathrm{NEI}} .
$$

According to (4) and (5), extrapolation of the secondorder polynomial fittings to the ordinate at the origin $\left(\left[\mathrm{M}^{+}\right]^{-1} \rightarrow 0\right)$ allows the retention factor due to any mechanism other than electrostatic interactions $\left(k_{\mathrm{NEI}}\right)$ to be calculated, since when $\left[\mathrm{M}^{+}\right]^{-1} \rightarrow 0$, then $k_{\mathrm{EI}}=0$. For a hypothetical infinite concentration of salts $\left(\right.$ when $\left[\mathrm{M}^{+}\right]^{-1} \rightarrow 0$ then $\left[\mathrm{M}^{+}\right] \rightarrow \infty$ ), there would be "infinite competition" (of the salts against the target analytes) for the electrostatically active sites of the stationary phase; this would completely eliminate the electrostatic contribution to the retention mechanism of the analytes.

From these calculated $k_{\text {NEI }}$ values, the percentage of contribution of the electrostatic interaction (\%EI) to the overall retention was calculated, according to (6), for each analyte and for the different of salt concentrations studied (Table 2):

$$
\% \mathrm{EI}=\frac{k_{\mathrm{EI}}}{k_{\exp }} \cdot 100 .
$$

For the lowest salt concentration, $0.25 \mathrm{mM}$, the contribution of the electrostatic interactions to the retention mechanism varied between $25 \%$ and $52 \%$ for $\mathrm{NH}_{4}{ }^{+}$, and between $26 \%$ and $49 \%$ for $K^{+}$. These decreased progressively as the salt concentration rose, observing, for a salt concentration of $2.5 \mathrm{mM}$, contributions between $6 \%$ and $23 \%$ for $\mathrm{NH}_{4}{ }^{+}$ and between $6 \%$ and $16 \%$ for $K^{+}$. These results are in good agreement with those found by McCalley working with four basic compounds [2] and by Kumar et al. for catecholamines [4].

The retention factors due to electrostatic interactions at a salt concentration of $0.25 \mathrm{mM}\left(k_{\mathrm{EI}}\right)_{0.25 \mathrm{mM}}$ were also calculated (Table 2). These values can be determined for (4) as the difference between the experimental retention factors at $0.25 \mathrm{mM}\left(k_{\exp }\right)$ and the retention factors for an infinite concentration of salts $\left(k_{\mathrm{NEI}}\right)$. Here, it should be recalled that these $k_{\mathrm{NEI}}$ values were estimated by extrapolation to zero of the experimental data (Table 1). Accordingly, the percentage values (Table 2 ) should be seen as a quantitative approximation to the electrostatic contribution to the overall retention.

\section{Conclusions}

The results obtained in the present work show that for charged MNNs separation in the ZIC-HILIC column is based on a shared mechanism of partition and interaction through weak electrostatic forces. The electrostatic contribution to retention was about $25-50 \%$ at low salt concentration in the eluent, although it should be noted that this contribution decreased significantly as the salt concentration rose. In order to exploit these interactions with a view to enhancing selectivity and resolution in ZIC-HILIC separations, the use of mobile phases at low salt concentrations should be considered.

\section{Acknowledgments}

The Ministerio de Ciencia e Innovación, Spain (Project CTQ 2011-24075), and Junta de Castilla y León (Grupo de Excelencia GR-65) are gratefully acknowledged for financial support. D. García-Gómez gratefully acknowledges financial assistance from Ministerio de Educación, Spain (FPU grant).

\section{References}

[1] A. J. Alpert, "Hydrophilic-interaction chromatography for the separation of peptides, nucleic acids and other polar compounds," Journal of Chromatography, vol. 499, pp. 177-196, 1990.

[2] D. V. McCalley, "Study of the selectivity, retention mechanisms and performance of alternative silica-based stationary phases for separation of ionised solutes in hydrophilic interaction chromatography," Journal of Chromatography A, vol. 1217, no. 20, pp. 3408-3417, 2010.

[3] S. Mysling, G. Palmisano, P. Hojrup, and M. ThaysenAndersen, "Utilizing ion-pairing hydrophilic interaction chromatography solid phase extraction for efficient glycopeptide enrichment in glycoproteomics," Analytical Chemistry, vol. 82, no. 13, pp. 5598-5609, 2010.

[4] A. Kumar, J. P. Hart, and D. V. McCalley, "Determination of catecholamines in urine using hydrophilic interaction chromatography with electrochemical detection," Journal of Chromatography A, vol. 1218, no. 25, pp. 3854-3861, 2011.

[5] A. J. Alpert, "Electrostatic repulsion hydrophilic interaction chromatography for isocratic separation of charged solutes and selective isolation of phosphopeptides," Analytical Chemistry, vol. 80, no. 1, pp. 62-76, 2008.

[6] D. V. McCalley, "Is hydrophilic interaction chromatography with silica columns a viable alternative to reversed-phase liquid chromatography for the analysis of ionisable compounds?" Journal of Chromatography A, vol. 1171, no. 1-2, pp. 46-55, 2007.

[7] J. Ruta, S. Rudaz, D. V. McCalley, J. L. Veuthey, and D. Guillarme, "A systematic investigation of the effect of sample diluent on peak shape in hydrophilic interaction liquid chromatography," Journal of Chromatography A, vol. 1217, no. 52, pp. 8230-8240, 2010.

[8] Y. Guo and S. Gaiki, "Retention and selectivity of stationary phases for hydrophilic interaction chromatography," Journal of Chromatography A, vol. 1218, no. 35, pp. 5920-5938, 2011.

[9] P. Jandera, "Stationary and mobile phases in hydrophilic interaction chromatography: a review," Analytica Chimica Acta, vol. 692, no. 1-2, pp. 1-25, 2011.

[10] Z. Hao, B. Xiao, and N. Weng, "Impact of column temperature and mobile phase components on selectivity of hydrophilic interaction chromatography (HILIC)," Journal of Separation Science, vol. 31, no. 9, pp. 1449-1464, 2008.

[11] A. E. Karatapanis, Y. C. Fiamegos, and C. D. Stalikas, "A revisit to the retention mechanism of hydrophilic interaction liquid 
chromatography using model organic compounds," Journal of Chromatography A, vol. 1218, no. 20, pp. 2871-2879, 2011.

[12] R.-I. Chirita, C. West, S. Zubrzycki, A. -L. Finaru, and C. Elfakir, "Investigations on the chromatographic behaviour of zwitterionic stationary phases used in hydrophilic interaction chromatography," Journal of Chromatography A, vol. 1218, no. 35, pp. 5939-5963, 2011.

[13] B. Buszewski and S. Noga, "Hydrophilic interaction liquid chromatography (HILIC) - a powerful separation technique ," Analytical and Bioanalytical Chemistry, vol. 402, no. 1, pp. 231-247, 2011.

[14] K. Jinno, N. S. Quiming, N. L. Denola, and Y. Saito, "Modeling of retention of adrenoreceptor agonists and antagonists on polar stationary phases in hydrophilic interaction chromatography: a review," Analytical and Bioanalytical Chemistry, vol. 393, no. 1, pp. 137-153, 2009.

[15] E. Rodríguez-Gonzalo, D. García-Gómez, and R. CarabiasMartínez, "Study of retention behaviour and mass spectrometry compatibility in zwitterionic hydrophilic interaction chromatography for the separation of modified nucleosides and nucleobases," Journal of Chromatography A, vol. 1218, no. 26, pp. 3994-4001, 2011.

[16] Y. Guo and S. Gaiki, "Retention behavior of small polar compounds on polar stationary phases in hydrophilic interaction chromatography," Journal of Chromatography A, vol. 1074, no. 1-2, pp. 71-80, 2005. 


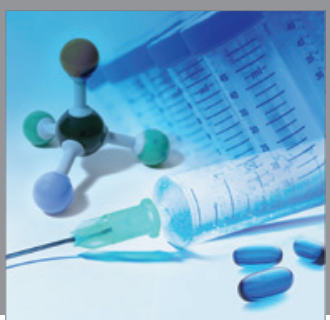

International Journal of

Medicinal Chemistry

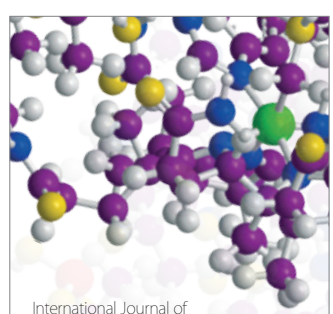

Carbohydrate Chemistry

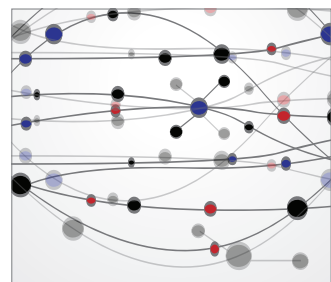

The Scientific World Journal
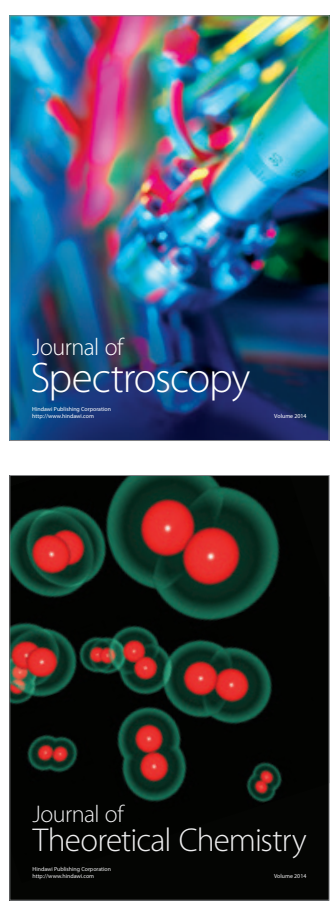
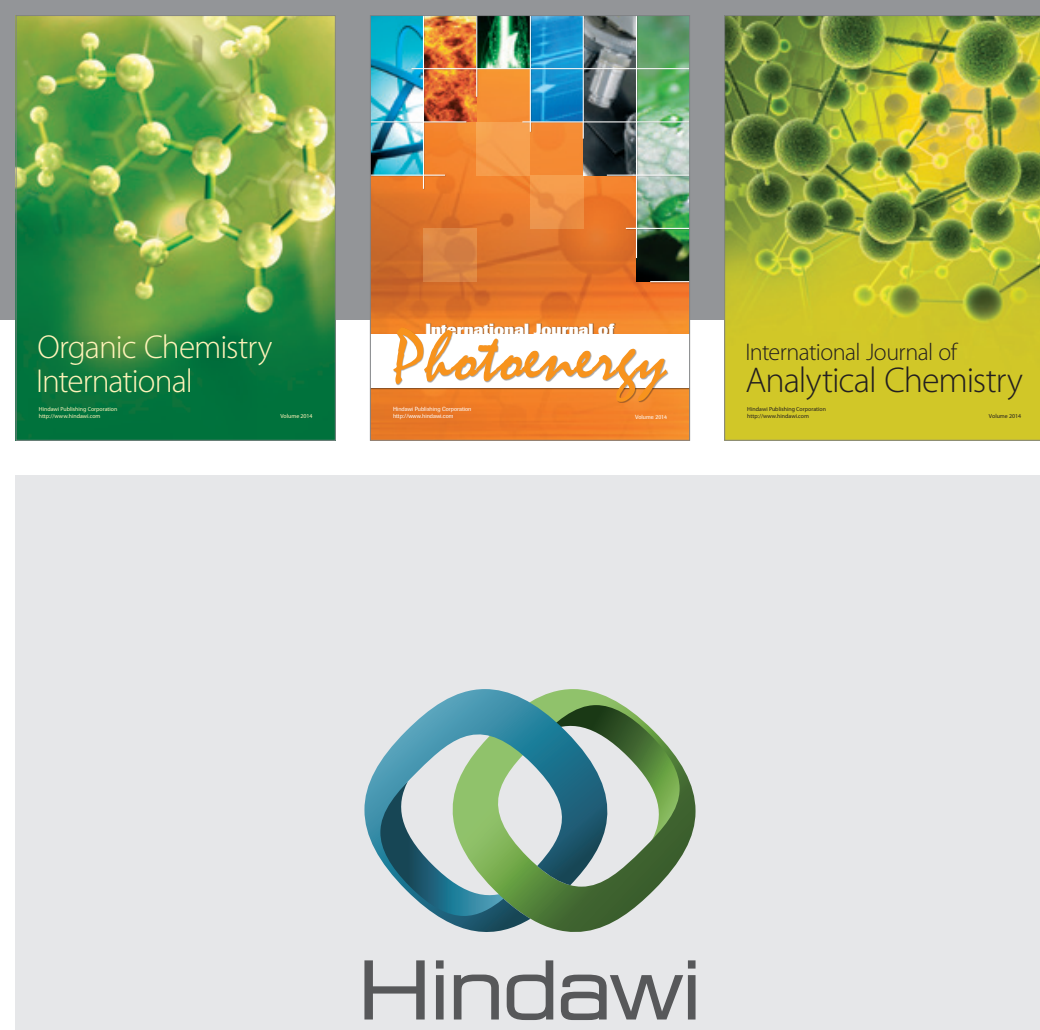

Submit your manuscripts at

http://www.hindawi.com
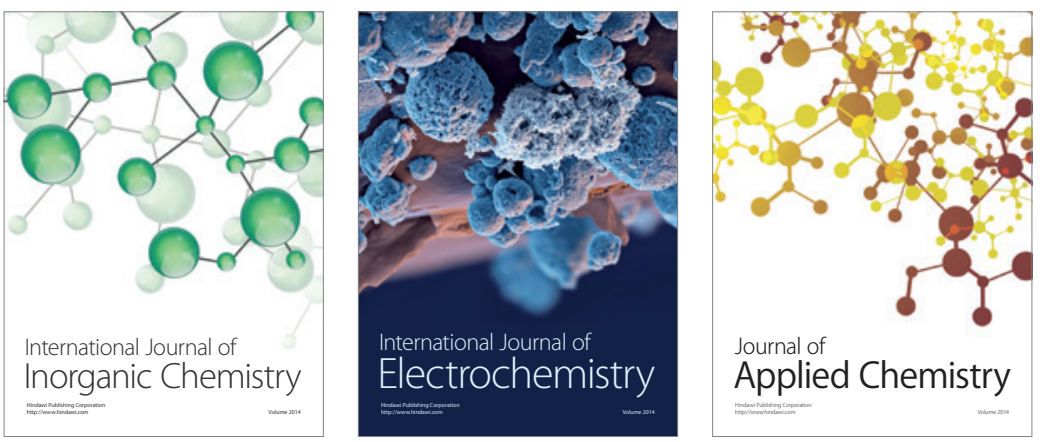

Journal of

Applied Chemistry
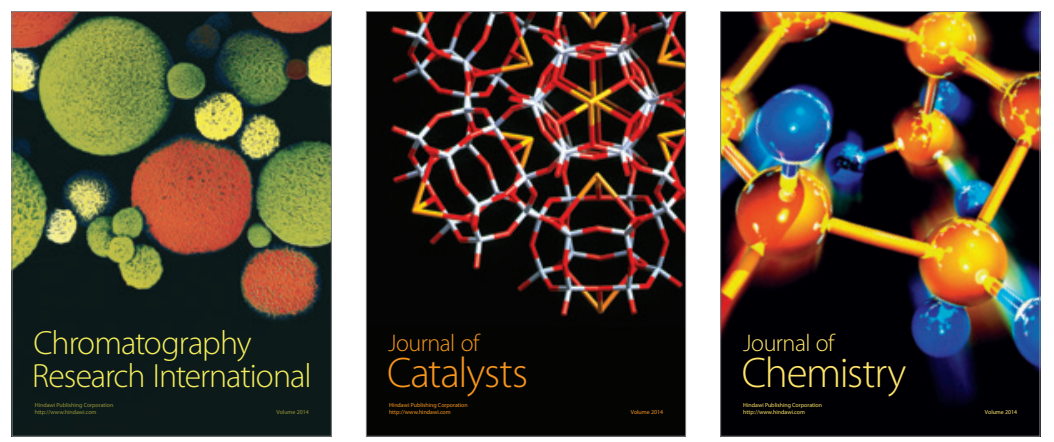
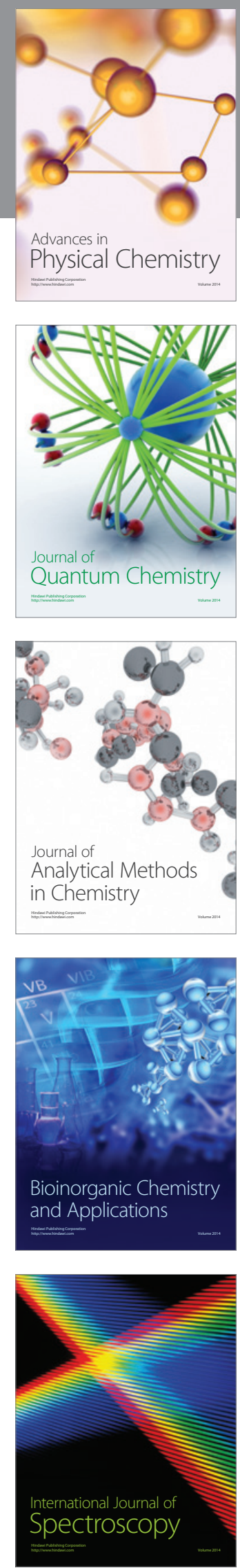